\title{
Mass spectrometric analysis and mutagenesis predict involvement of multiple cysteines in redox regulation of the skeletal muscle ryanodine receptor ion channel complex
}

\author{
This article was published in the following Dove Press journal: \\ Research and Reports in Biology \\ 20 January 2011 \\ Number of times this article has been viewed
}

Evgeniy V Petrotchenko $1,2,4$

Naohiro Yamaguchi ${ }^{1,3,4}$

Daniel A Pasek'

Christoph H Borchers ${ }^{1,2}$

Gerhard Meissner'

'Department of Biochemistry and Biophysics, University of North

Carolina, Chapel Hill, NC, USA; 'University of Victoria, Genome BC Proteomics Centre, Victoria, British Columbia, Canada; ${ }^{3}$ Department of Regenerative Medicine and Cell Biology, Medical University of South Carolina, Charleston, SC, USA

${ }^{4}$ Contributed equally to the work
Correspondence: Gerhard Meissner Department of Biochemistry and Biophysics, University of North Carolina, Chapel Hill, NC 27599-7260, USA

$\mathrm{Tel}+|919966502|$

$\mathrm{Fax}+19199662852$

Email meissner@med.unc.edu
Abstract: The tetrameric skeletal muscle ryanodine receptor ion channel complex (RyR1) contains a large number of free cysteines that are potential targets for redox-active molecules. Here, we report the mass spectrometric analysis of free thiols in RyR1 using the lipophilic, thiol-specific probe monobromobimane (MBB). In the presence of reduced glutathione, MBB labeled 14 cysteines per RyR1 subunit in tryptic peptides in five of five experiments. Forty-six additional MBB-labeled cysteines per RyR1 subunit were detected with lower frequency in tryptic peptides, bringing the total number of MBB-labeled cysteines to 60 per RyR1 subunit. A combination of fluorescence detection and mass spectrometry of RyR1, labeled in the presence of reduced and oxidized glutathione, identified two redox-sensitive cysteines (C1040 and C1303). Regulation of RyR activity by reduced and oxidized glutathione was investigated in skeletal muscle mutant RyR1s in which 18 cysteines were substituted with serine or alanine, using a $\left[{ }^{3} \mathrm{H}\right]$ ryanodine ligand binding assay. Three single-site RyR1 mutants (C1781S, C2436S, and $\mathrm{C} 2606 \mathrm{~S}$ ) and two multisite mutants with five and seven substituted cysteines exhibited a reduced redox response compared with wild-type RyR1. The results suggest that multiple cysteines determine the redox state and activity of RyR1.

Keywords: mass spectrometry, mutagenesis, ryanodine receptor, redox modification of cysteines

\section{Introduction}

Ryanodine receptor ion channels (RyRs) control diverse cellular functions by releasing $\mathrm{Ca}^{2+}$ from an intracellular compartment, ie, the sarcoplasmic reticulum. Skeletal muscle type 1 (RyR1) and cardiac muscle type 2 (RyR2) ryanodine receptors play a pivotal role by releasing the $\mathrm{Ca}^{2+}$ ions necessary for muscle contraction. The RyRs are redox-sensitive $\mathrm{Ca}^{2+}$ channels ${ }^{1-4}$ composed of four RyR $560 \mathrm{kDa}$ peptide subunits, $12 \mathrm{kDa}$ tacrolimus binding proteins, and multiple associated proteins for a total molecular weight of $>2500$ $\mathrm{kDa} .^{5,6}$ The tetrameric RyR1 has 404 cysteines, with 100 cysteines per $565 \mathrm{kD}$ subunit, and one per tacrolimus binding protein, respectively. RyR1 redox state and activity are dependent on oxygen tension, ${ }^{7}$ glutathione redox potential, ${ }^{7,8}$ effector molecules $\left(\mathrm{Ca}^{2+}\right.$, $\mathrm{Mg}^{2+}$ ) that control RyR1 channel activity, ${ }^{9}$ and reactive oxygen molecules that are produced in working muscle at a low basal rate. ${ }^{1}$ Aberrant S-nitrosylation of RyRs has been implicated in a malignant hyperthermia mouse model ${ }^{10}$ and in dystrophic muscle. ${ }^{11,12}$

A number of RyR1 redox-reactive cysteines have been identified. Site-directed mutagenesis showed that at physiologic oxygen concentration, nitric oxide specifically 
S-nitrosylates one cysteine in RyR1 (Cys3635). ${ }^{13}$ Mass spectrometric analysis identified seven hyperreactive RyR1 cysteines that were selectively labeled by 7-diethylamino-3-(4'maleimidylphenyl)-4-methylcoumarin under conditions that favored channel closing. ${ }^{14}$ Nine RyR1 cysteines were shown to be endogenously S-nitrosylated or S-glutathionylated. ${ }^{15}$ Another three residues were modified by exogenous reactive oxygen and nitrogen molecules. However, the contribution of individual cysteines toward the redox regulation of RyR1 is not known, with the exception of RyR1-C3635. ${ }^{13}$

In the present study, we used a previously developed procedure $^{16}$ and mutagenesis to identify RyR1 cysteines involved in redox regulation of RyR1. Free thiols in skeletal muscle sarcoplasmic reticulum membranes enriched in RyR1 were labeled with the lipophilic, thiol-selective, and fluorescent reagent monobromobimane $(\mathrm{MBB})$ in the presence of reduced and oxidized glutathione. Tryptic proteolysis of MBB-labeled, purified RyR1 protein and mass spectrometric analysis of MBB-labeled peptides identified 60 free thiols per RyR1 subunit in the presence of reduced glutathione and two thiols that likely formed disulfides in the presence of oxidized glutathione. Site-directed mutagenesis revealed three cysteines that are involved in the functional redox modulation of RyR1 by reduced and oxidized glutathione.

\section{Materials and methods Preparation of sarcoplasmic reticulum membranes}

Rabbit skeletal muscle sarcoplasmic reticulum membranes enriched in RyR1 were isolated in the presence of protease inhibitors, as described elsewhere. ${ }^{17}$

\section{MBB-labeling, purification, and digestion of RyR I}

Labeling of sarcoplasmic reticulum membranes with MBB and digestion of purified MBB-labeled RyR1 with trypsin have been described. ${ }^{16}$ Briefly, rabbit skeletal muscle sarcoplasmic reticulum membranes enriched in RyR1 were reacted for 150 minutes at $30^{\circ} \mathrm{C}$ with $5 \mathrm{mM}$ reduced or oxidized glutathione in buffer A, ie, $0.15 \mathrm{M} \mathrm{NaCl}, 20 \mathrm{mM}$ Na-PIPES, pH 7 buffer containing $100 \mu \mathrm{M}$ EGTA, $100 \mu \mathrm{M}$ $\mathrm{Ca}^{2+}$ (approximately $10 \mu \mathrm{M}$ free $\mathrm{Ca}^{2+}$ ), and protease inhibitors. Membranes were sedimented, resuspended in buffer A containing $50 \mu \mathrm{M}$ reduced or oxidized glutathione, respectively, at a protein concentration of $3 \mathrm{mg} / \mathrm{mL}$, reacted for one hour at $24^{\circ} \mathrm{C}$ in the dark with an excess of MBB ( $1 \mathrm{mM})$, and solubilized by the addition of two volumes of 1.5 M NaCl, 20 mM Na-PIPES, pH 7.0 buffer containing
2.2\% CHAPS, $7.5 \mathrm{mg} / \mathrm{mL}$ soybean phosphatidylcholine, and protease inhibitors. MBB-labeled RyR1 s were purified as $30 \mathrm{~S}$ protein complexes on sucrose gradients in the presence of $1 \%$ CHAPS but in the absence of phospholipids. To determine the position of MBB-labeled RyR1 on gradients, sarcoplasmic reticulum membranes were reacted with the RyR-specific probe $\left[{ }^{3} \mathrm{H}\right]$ ryanodine (3 $\left.\mathrm{nM}\right)$, solubilized with CHAPS, placed on a separate gradient, and centrifuged. Fractions containing MBB-labeled RyR1 were digested with immobilized trypsin for 72 hours at $24^{\circ} \mathrm{C}$. Completion of digestion was confirmed by sodium dodecyl sulfate polyacrylamide gel electrophoresis followed by silver staining.

\section{Mass spectrometric analyses of MBB-labeled RyRI peptides}

Tryptic peptides were separated by reverse-phase highpressure liquid chromatography (HPLC) and analyzed on a 4700 Proteomics Analyzer matrix-assisted laser desorption/ ionization (MALDI)-time of flight (TOF)/TOF mass spectrometry (MS; Applied Biosystems, Foster City, CA, USA) as described. ${ }^{16}$ To assign the MBB-modified peptide peaks in the MALDI MS spectra, the MS-Fit program (Protein Prospector; MS Facility, UCSF, Berkely, CA) was used. Additionally, spectra were screened for the presence of ion signals at $190.07 \pm 0.1 \mathrm{Da}$ apart using a software program. ${ }^{16}$ Peaks matching the theoretically predicted masses for MBB-modified peptides were selected for MS/MS analysis by MALDI-TOF/TOF. The fragment ion spectra were manually matched to the predicted peptide fragmentation spectra generated by MS-Product (Protein Prospector).

\section{Construction and expression of mutant cDNAs}

Single and multiple base changes of rabbit RyR1 cDNA were performed by PfuTurbo ${ }^{\circledR}$ (Stratagene, La Jolla, CA). cDNA fragments containing the mutation sites were cloned into vectors and used for polymerase-based chain reaction using mutagenic oligonucleotides and the QuikChange site-directed mutagenesis kit (Stratagene), as described previously. ${ }^{18}$ The complete mutated fragments were confirmed by DNA sequencing. The fragments with mutations were cloned back into the original positions by standard cloning techniques. Finally, full-length RyR1 cDNAs with the mutations were cloned into a pCMV5 (ClaI/XbaI) expression vector. The cDNA of RyR2 was provided by Dr Junichi Nakai, of Saitama University, Japan. Nucleotide numbering was as described elsewhere. ${ }^{19}$ 


\section{Expression of wild-type and mutant RyR I proteins in HEK 293 cells}

Wild-type RyR $1,{ }^{18} \mathrm{RyR} 2,{ }^{20}$ and RyR1 mutant cDNAs were transiently expressed in HEK293 cells. Cells were transfected with FuGENE 6 (Roche Applied Science, Branford, CT) according to the manufacturer's instructions. Cells were maintained at $37^{\circ} \mathrm{C}$ and $5 \% \mathrm{CO}_{2}$ in high-glucose Dulbecco's Modified Eagle's Medium containing 10\% fetal bovine serum and plated the day before transfection. For each $10 \mathrm{~cm}$ tissue culture dish, $3.5 \mu \mathrm{g}$ of cDNA was used. Cells were harvested 48 hours after transfection. Crude membrane fractions were prepared in the presence of protease inhibitors as described previously. ${ }^{18}$

\section{$\left[{ }^{3} \mathrm{H}\right]$ Ryanodine binding}

The highly specific plant alkaloid ryanodine is widely used as a probe for RyR channel activity because of its preferential binding to the open channel. ${ }^{21}\left[{ }^{3} \mathrm{H}\right]$ Ryanodine binding experiments were performed with crude membrane fractions from HEK293 cells. Unless otherwise indicated, membranes were incubated in the presence of protease inhibitors with $3 \mathrm{nM}\left[{ }^{3} \mathrm{H}\right]$ ryanodine in $20 \mathrm{mM}$ imidazole, $\mathrm{pH} 7.0,250 \mathrm{mM}$ $\mathrm{KCl}, 25 \mu \mathrm{M}$ free $\mathrm{Ca}^{2+}\left(75 \mu \mathrm{M} \mathrm{Ca}^{2+}\right.$ and $50 \mu \mathrm{M}$ EGTA), and $5 \mathrm{mM}$ reduced or oxidized glutathione. Nonspecific binding was determined using a 1000-2000-fold excess of unlabeled ryanodine. After 20 hours at $24^{\circ} \mathrm{C}$, samples were diluted with seven volumes of ice-cold water and placed on Whatman GF/B filters preincubated with $2 \%$ polyethyleneimine in water. Filters were washed with three $5 \mathrm{~mL}$ ice-cold $100 \mathrm{mM}$ $\mathrm{KCl}, 1 \mathrm{mM}$ K-PIPES, pH 7.0 solution. The radioactivity remaining with the filters was determined by liquid scintillation counting to obtain bound $\left[{ }^{3} \mathrm{H}\right]$ ryanodine.

\section{Data analysis}

Results are given as mean \pm standard error of the mean. Differences between recombinant wild-type RyR1 and mutants were analyzed with the Student's $t$-test. $P<0.05$ was considered to be statistically significant.

\section{Results and discussion Identification of cysteinyl residues that react with $\mathrm{MBB}$}

To identify free thiols in the presence of reduced and oxidized glutathione, sarcoplasmic reticulum membranes isolated from rabbit skeletal muscle were reacted with $1 \mathrm{mM}$ MBB after treatment with $5 \mathrm{mM}$ reduced or oxidized glutathione, respectively. Analysis of the labeled and purified RyR1 indicated that MBB-labeled numbers in the reduced receptor were $37.5 \pm 1.0$ thiols/per RyR1 subunit $(n=5)$. Exposure of sarcoplasmic reticulum membranes to oxidized glutathione reduced the

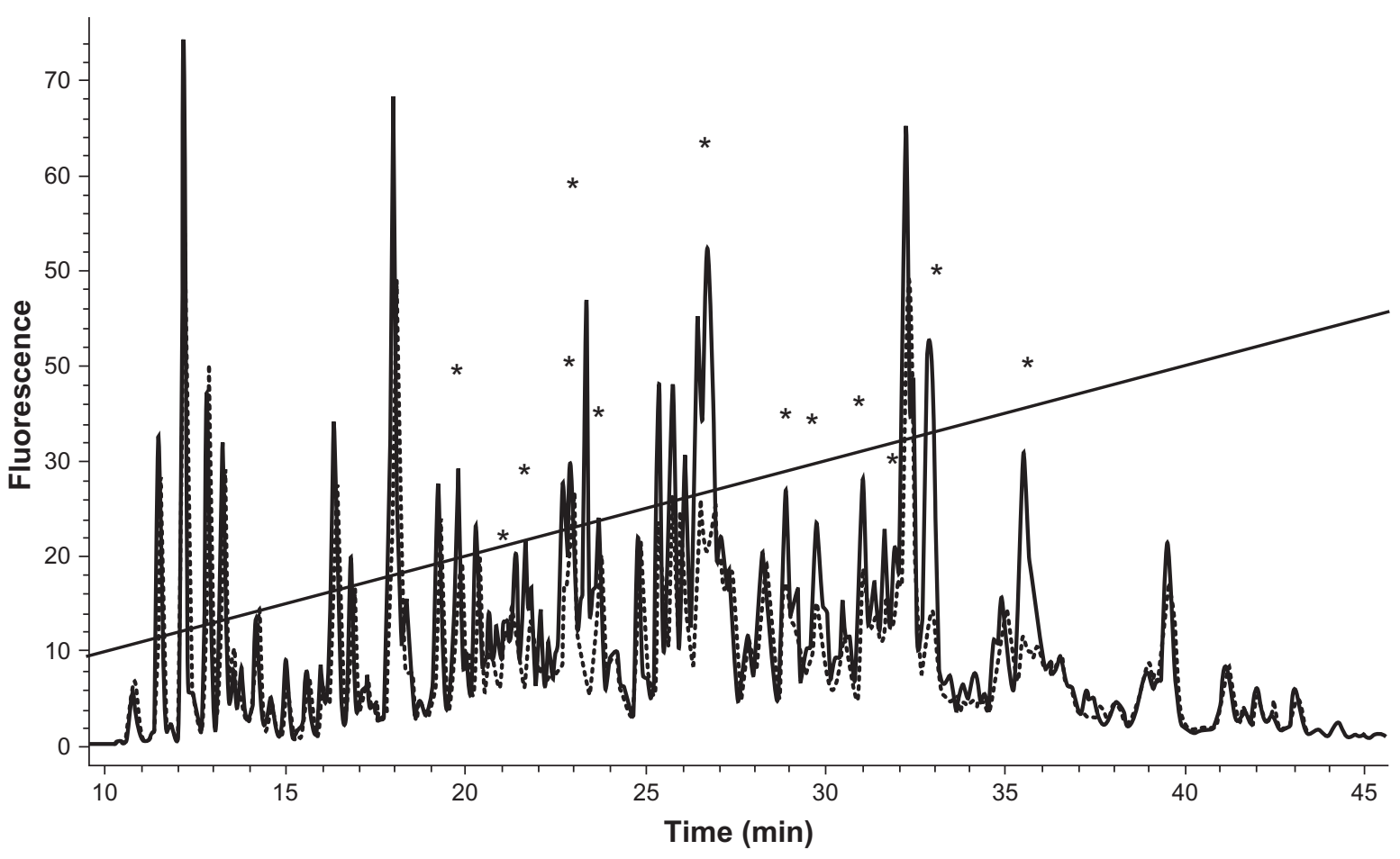

Figure I HPLC fluorescence diagram of tryptic digests of RyRI labeled with monobromobimane under reducing (solid line) and oxidizing (dotted line) conditions. Note: *Noticeable differences in peak intensity under reduced and oxidized conditions. HPLC fractions at 24 minutes (Figure 2 ) and 27 minutes (Figure 3 ) were analyzed using MALDI-MS and MALDI tandem MS analyses.

Abbreviations: HPLC, high-pressure liquid chromatography; MALDI, matrix-assisted laser desorption/ionization; MS, mass spectrometry; RyRI, skeletal muscle type I. 
number of MBB-labeled thiols/RyR1 subunit to $30.8 \pm 2.7$ $(n=5)$, in reasonable agreement with a previous study.

The purified MBB-labeled RyR1 protein was digested with immobilized trypsin, and the resulting peptides were separated by reverse-phase HPLC with fluorescence detection. Figure 1 shows two representative superimposed HPLC fluorescence chromatograms of RyR1 tryptic peptides obtained from two samples treated with $5 \mathrm{mM}$ reduced glutathione (solid lines) or oxidized glutathione (dotted lines) and then labeled with MBB. Increased fluorescence signals

Table I Identification of MBB-labeled cysteines in RyRI under reducing conditions.

\begin{tabular}{|c|c|c|c|c|c|}
\hline $\begin{array}{l}\text { RyRI } \\
\text { aa }\end{array}$ & $\begin{array}{l}\text { aa/ } \\
\text { peptide }^{a}\end{array}$ & $\begin{array}{l}\text { mBB- } \\
\text { Cyss }^{b}\end{array}$ & $\begin{array}{l}\text { RyRI } \\
\text { aa }\end{array}$ & $\begin{array}{l}\text { aal } \\
\text { peptide }^{a}\end{array}$ & $\begin{array}{l}\text { mBB- } \\
\text { Cys }^{b}\end{array}$ \\
\hline 36 & 11 & 5 & 146 & 25 & 1 \\
\hline 315 & 7 & $5+1$ & 346 & 25 & I \\
\hline 811 & 17 & $5+1$ & 845 & 25 & $I+I$ \\
\hline 1040 & 8 & $5+1$ & 854 & 25 & $I+I$ \\
\hline $159 \mid$ & 9 & $5+1$ & 1447 & 30 & I \\
\hline 1647 & 10 & $5+1$ & 1947 & 18 & I \\
\hline 2232 & 7 & $5+1$ & 2310 & 19 & I \\
\hline 2233 & 7 & 5 & 2651 & 3 & I \\
\hline 2326 & 14 & $5+1$ & 2656 & 23 & 1 \\
\hline 2363 & 10 & 5 & 2704 & 24 & I \\
\hline 2436 & 12 & $5+1$ & 3170 & 12 & I \\
\hline 3044 & 9 & $5+1$ & 3839 & 18 & 1 \\
\hline 3635 & 7 & 5 & 3892 & 18 & $I+I$ \\
\hline \multirow[t]{2}{*}{3786} & 14 & $5+1$ & 4876 & 17 & I \\
\hline & & & 4882 & 17 & 1 \\
\hline 24 & 14 & $4+1$ & & & \\
\hline 253 & 14 & 4 & 47 & 31 & $0+1$ \\
\hline 937 & 15 & 4 & 65 & 31 & 0 \\
\hline 1303 & 20 & 4 & 66 & 31 & 0 \\
\hline 2021 & 15 & $4+1$ & 206 & 42 & 0 \\
\hline 2237 & 7 & 4 & 208 & 42 & 0 \\
\hline 2611 & 13 & 4 & 209 & 42 & 0 \\
\hline 3193 & 11 & 4 & 230 & 42 & $0+1$ \\
\hline 3240 & 21 & 4 & 490 & 19 & 0 \\
\hline 5018 & 12 & 4 & 537 & 16 & $0+1$ \\
\hline 393 & 10 & 3 & 566 & 31 & 0 \\
\hline 604 & 17 & 3 & 746 & 75 & $0+1$ \\
\hline 607 & 17 & 3 & 747 & 75 & 0 \\
\hline 609 & 17 & 3 & 762 & 30 & 0 \\
\hline 906 & 16 & $3+1$ & $|15|$ & 59 & $0+1$ \\
\hline 1674 & 9 & $3+1$ & 1192 & 12 & 0 \\
\hline 2305 & 19 & $3+1$ & 1217 & 28 & $0+1$ \\
\hline 2555 & 12 & $3+1$ & 1489 & 20 & 0 \\
\hline 2606 & 13 & $3+1$ & 1492 & 20 & 0 \\
\hline 2702 & 24 & 3 & 1518 & 26 & 0 \\
\hline 3402 & 8 & $3+1$ & 1630 & 23 & 0 \\
\hline 3650 & 10 & 3 & 1686 & 28 & 0 \\
\hline 5027 & 12 & $3+1$ & $|78|$ & 38 & 0 \\
\hline
\end{tabular}

Table I(Continued)

\begin{tabular}{|c|c|c|c|c|c|}
\hline $\begin{array}{l}\text { RyR I } \\
\text { aa }\end{array}$ & $\begin{array}{l}\text { aal } \\
\text { peptide }^{a}\end{array}$ & $\begin{array}{l}\text { mBB- } \\
\text { Cys }^{b}\end{array}$ & $\begin{array}{l}\text { RyRI } \\
\text { aa }\end{array}$ & $\begin{array}{l}\text { aal } \\
\text { peptide }\end{array}$ & $\begin{array}{l}\text { mBB- } \\
\text { Cys }^{b}\end{array}$ \\
\hline & & & 2042 & 34 & 0 \\
\hline 120 & 10 & $2+1$ & 2158 & 23 & 0 \\
\hline 305 & 17 & $2+1$ & 3014 & 23 & 0 \\
\hline 1269 & 28 & $2+1$ & 3067 & 20 & $0+1$ \\
\hline 1724 & 17 & 2 & 3165 & 44 & 0 \\
\hline 1940 & 18 & $2+1$ & 3216 & 26 & 0 \\
\hline 2240 & 7 & 2 & 3278 & 21 & $0+1$ \\
\hline 2565 & 11 & 2 & 3304 & 24 & 0 \\
\hline \multirow[t]{10}{*}{3525} & 21 & $2+1$ & 3733 & 25 & 0 \\
\hline & & & 3918 & 21 & 0 \\
\hline & & & 3973 & 25 & 0 \\
\hline & & & 4114 & 30 & $0+1$ \\
\hline & & & 4238 & 65 & $0+1$ \\
\hline & & & 4645 & 84 & 0 \\
\hline & & & 4657 & 84 & 0 \\
\hline & & & 4663 & 84 & 0 \\
\hline & & & 4958 & 41 & $0+1$ \\
\hline & & & 4961 & 41 & 0 \\
\hline
\end{tabular}

Notes: amino acids per tryptic peptide; 'bmonobromobimane-labeled cysteine detected in tryptic peptides (number of experiments out of five experiments). The second number indicates monobromobimane-labeled cysteines detected in V8 peptides $(n=1)$

Abbreviation: RyRI, skeletal muscle type I.

(labeled with *) were observed in the sample that was labeled under reducing conditions (solid lines) compared with that under oxidizing conditions (dotted lines). Fractions exhibiting fluorescence signals were lyophilized and subsequently analyzed by mass spectrometric analysis using MALDI-MS and MS/MS. ${ }^{16}$ Table 1 summarizes the MS results obtained under reducing conditions. Of the 100 cysteines in each RyR1 subunit, 60 MBB-modified cysteines were observed with varying frequency. Under reducing conditions in five experiments, 14 MBB-modified cysteines were detected in all five experiments, 10 in four experiments, 13 in three experiments, eight in two experiments, and 15 in one experiment. Forty cysteines either did not react with MBB or were not detected as MBB-modified cysteines by MS. With some exceptions, the frequency of detecting MBB-labeled peptides was high in peptides of less than 20 amino acids, and low as peptide length exceeded 20 amino acids. Thus, the frequency of detecting MBB-modified cysteines likely depended, at least in part, on the length of the tryptic peptides. In two previous studies, in which seven ${ }^{14}$ and $12^{15}$ redoxmodified cysteines were identified by MS analysis, peptide size may also have had a limiting role, because all modified cysteines reported were present in peptides that had 20 or less amino acids. To decrease peptide size, tryptic peptides were treated in one experiment with immobilized V8 protease. 
Digestion with V8 resulted in the tentative identification of 11 additional MBB-modified cysteines (Table 1).

In addition to revealing MBB-labeled peptides, LCMALDI-MS analysis can provide information about the redox state of cysteines in RyR1 under reducing and oxidizing conditions. ${ }^{16}$ To identify redox-sensitive cysteines, HPLC fractions of peptides obtained from RyR1 under reducing (Figure 1, solid line) and oxidizing (dotted line) conditions were compared by MALDI-MS. We identified two cysteines (C1040 and C1303) in two separate tryptic peptides (Figures 2 and 3) that showed under reducing conditions a significantly higher intensity in a peak doublet $190.07 \pm 0.1$ Da apart, which is characteristic for MBB-labeled peptides. ${ }^{16}$ Significance was ascertained by statistical analysis of the logarithmic peak intensity ratios of mass spectra of samples treated with reduced glutathione and oxidized glutathione. The identity of the peptides was confirmed by MS/MS analysis. Evidence for a third redox-sensitive cysteine (C2326) was obtained previously. ${ }^{16}$ Collectively, the data suggest that cysteines that react with MBB under reducing conditions may be present in a partially oxidized state. Replacement of reduced glutathione with oxidized glutathione shifted the redox state of cysteines from a free to an oxidized state but without fully oxidizing cysteines.

\section{Redox modulation of RyRI cysteine mutants by glutathione redox state}

To gain a better understanding of the effects of a change in glutathione redox potential on RyR1 activity, we studied the redox behavior of single- and multiple-site RyR1 cysteine mutants. Full-length RyR1 single-site mutants were generated by substituting 18 cysteine residues with serine or alanine (Table 2). Single-site RyR1 mutants included three redox-sensitive cysteines identified by $\mathrm{MS}^{16}$ (Figures 2 and 3), seven hyperreactive cysteine residues implicated in RyR1 function, ${ }^{14}$ and six additional cysteines
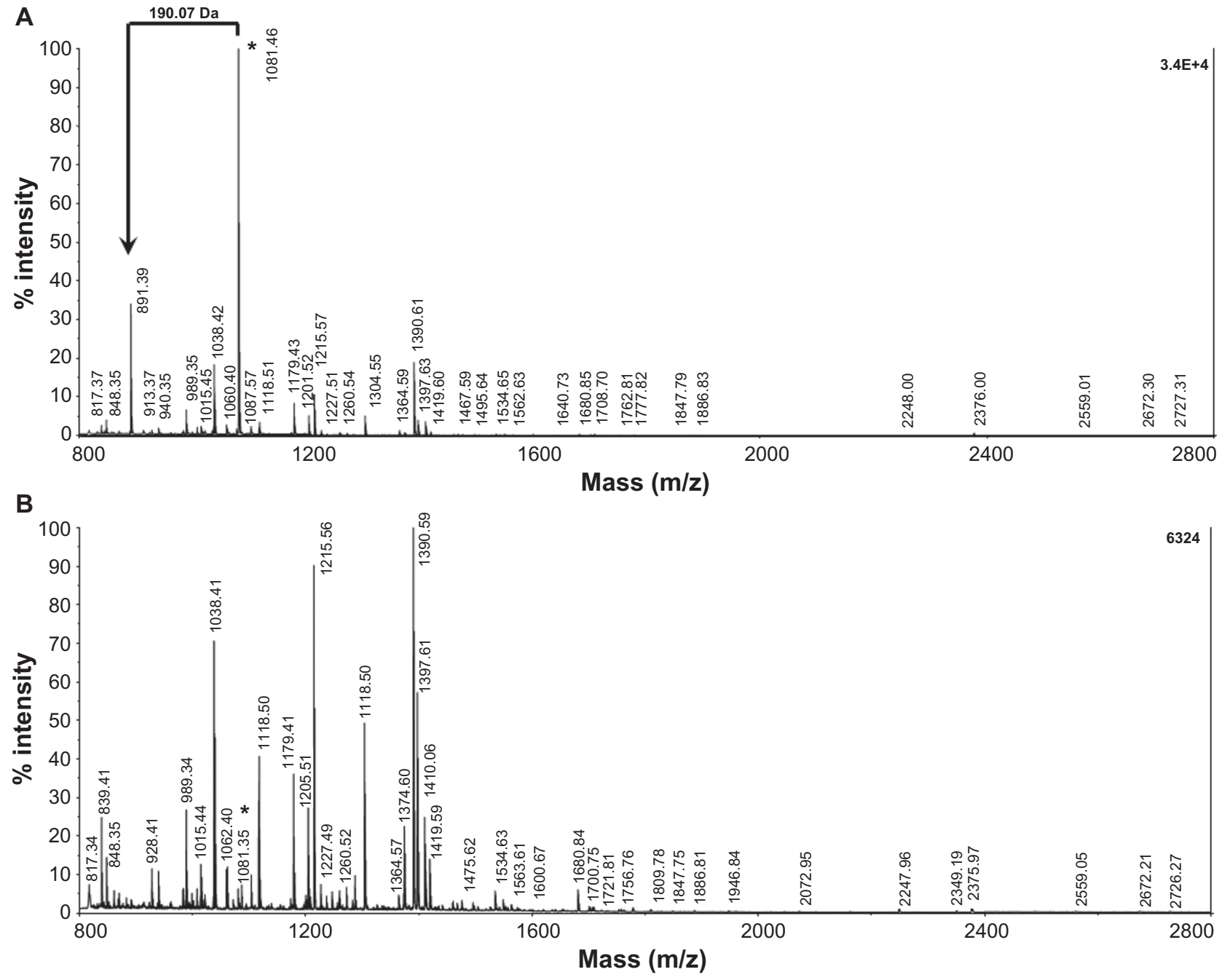

Figure 2 (Continued) 

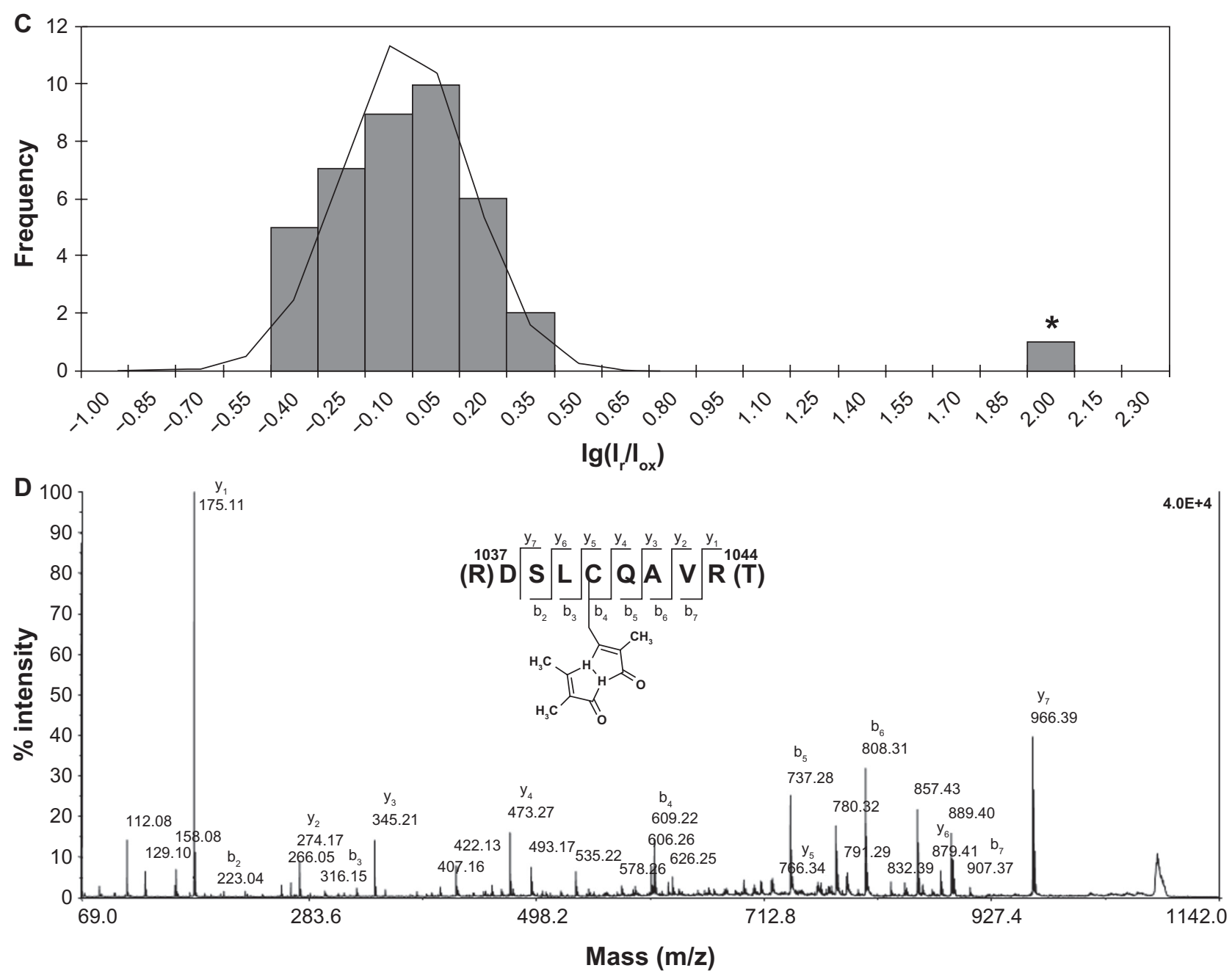

Figure 2 Identification of redox-sensitive Cys-1040 by mass spectrometry. A, B) MALDI mass spectra of the chromatographic fractions of trypsin digest of the monobromobimane-modified RyRI in the presence of reduced and oxidized glutathione, respectively. Monobromobimane-modified peptides manifest in MALDI mass spectra as characteristic pairs of peaks $190 \mathrm{Da}$ apart, due to partial photocleavage of the monobromobimane moiety. C) Statistical analysis of the logarithms of the MS peak intensity ratios of the reduced glutathione (Panel A) and oxidized glutathione (Panel B) samples. D) MS/MS analysis of the peptide containing the redox-sensitive monobromobimanemodified cysteine.

Note: *Value corresponding to the peptide containing the redox-sensitive cysteine 1040.

Abbreviations: MALDI, matrix-assisted laser desorption/ionization; MS, mass spectrometry; RyRI, skeletal muscle type I.

not conserved in RyR2 (Table 2). Mutation of three cysteines (C1781, C2436, and C2606) resulted in a significantly reduced redox response compared with wild-type RyR1. None of the three cysteine mutants (C1040S, C1303S, and C2326S) identified as redox-sensitive cysteines by $\mathrm{MS}^{16}$ (Figures 2 and 3) showed a significant change in activity in the presence of oxidized glutathione compared with reduced glutathione. We also found that among the seven hyperreactive cysteines previously implicated in RyR1 function, ${ }^{14}$ only two (C2436S and C2606S) showed a significantly decreased redox response compared with wild-type RyR1. The reason for this discrepancy is not clear but could have been due to the fact that RyR1 redox state and activity are dependent on $\mathrm{Ca}^{2+}$, which controls RyR1 channel activity. ${ }^{9}$ The seven hyperreactive cysteines were identified under conditions that favored channel closing, whereas in the present study RyR1 channels were partially activated by $\mathrm{Ca}^{2+}$.

Next, we sought to determine whether mutagenesis of several cysteines eliminates the redox response in RyR1. Five cysteines (RyR1-5Cys, Figure 4A) and seven cysteines (RyR1-7Cys, Figure 4B) were mutagenized simultaneously in RyR1. Mutations in RyR1-5Cys included the three redox-active cysteines (C1781, C2436, and C2606) identified in this study (Table 2). Mutations in RyR1-7Cys corresponded to the seven hyperreactive cysteines that have been suggested to play a role in redox sensing of RyR1. ${ }^{14}$ The two multisite mutants exhibited a smaller redox response than the single-site mutants, but without 


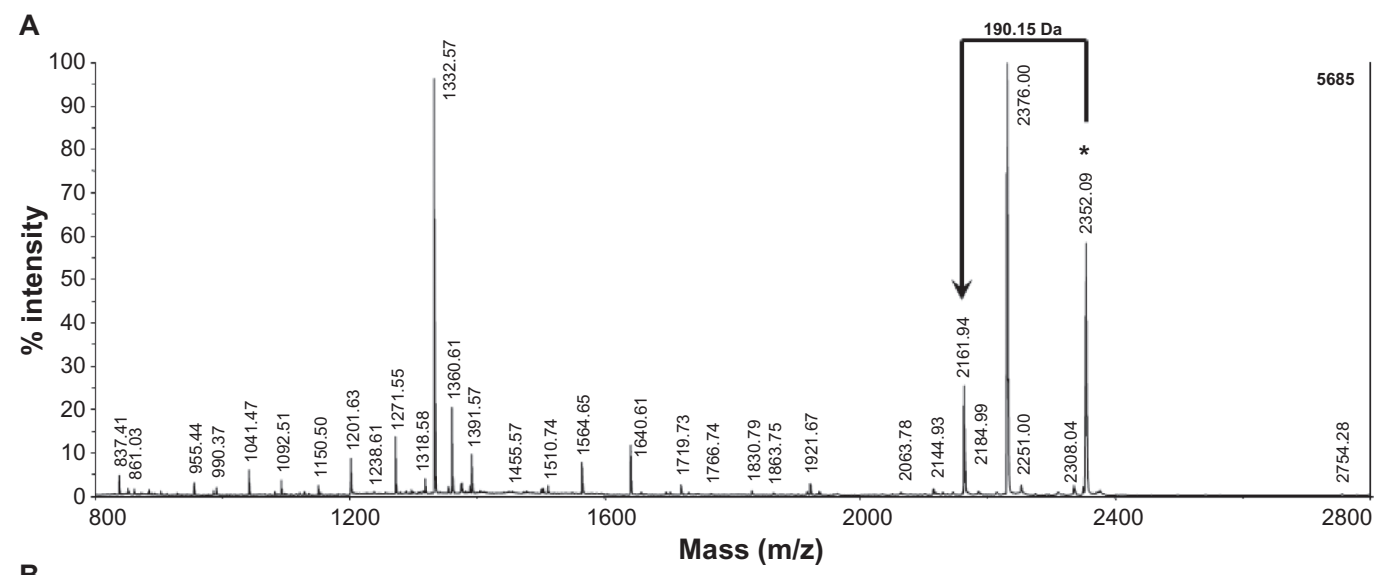

B
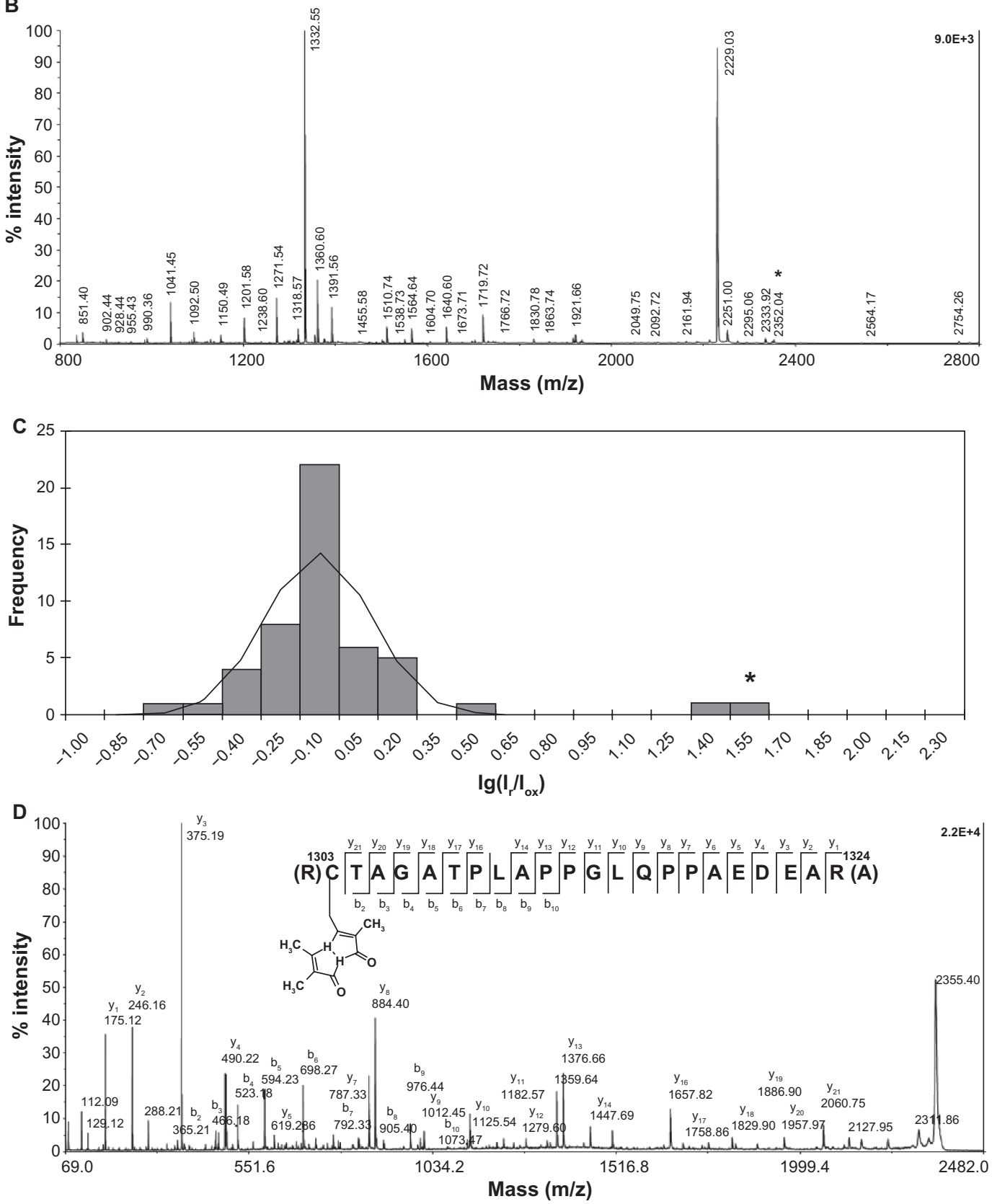

Figure 3 Identification of the redox-sensitive Cys-1303 by mass spectrometry. Panels are as in Figure 2. 
Table 2 Effects of GSSG and GSH on recombinant WT-RyRI, WT-RyR2 and mutant RyRI activities.

\begin{tabular}{|c|c|c|c|}
\hline Mutants & GSSG/GSH $^{c}$ & $\begin{array}{l}\text { RyR2 } \\
\text { aa }^{\text {d }}\end{array}$ & $\begin{array}{l}\text { Detected as redox } \\
\text { sensitive thiol by MS }\end{array}$ \\
\hline WT-RyRI & $3.27 \pm 0.14(32)$ & & \\
\hline RyRI-C207S & $3.00 \pm 0.35(5)$ & $S$ & \\
\hline RyRI-C393S & $2.90 \pm 0.1 I(7)$ & $S$ & \\
\hline RyRI-C854S & $3.25 \pm 0.44(4)$ & 1 & \\
\hline RyRI-CI040S b & $3.18 \pm 0.29(7)$ & $\mathrm{R}$ & $\sqrt{ }$ \\
\hline RyRI-CI303S b & $3.15 \pm 0.31(8)$ & $\mathrm{K}$ & $\sqrt{ }$ \\
\hline RyRI-CI447S & $3.20 \pm 0.42(4)$ & $\mathrm{N}$ & \\
\hline RyRI-CI648S & $2.95 \pm 0.22(5)$ & $S$ & \\
\hline RyRI-CI78IS & $2.45 \pm 0.16(5)^{*}$ & $S$ & \\
\hline RyRI-C2232S & $3.30 \pm 0.30(4)$ & & \\
\hline RyRI-C2233S & $3.15 \pm 0.53(3)$ & & \\
\hline RyRI-C2326S & $3.05 \pm 0.44(5)$ & v & $\sqrt{ }$ \\
\hline RyR I-C2436S & $2.35 \pm 0.26(7)^{*}$ & & \\
\hline RyRI-C2565S b & $2.64 \pm 0.26(7)$ & & \\
\hline RyR I-C2606S & $2.78 \pm 0.26(8)^{*}$ & & \\
\hline RyR I-C26I I S & $3.28 \pm 0.36(6)$ & & \\
\hline RyRI-C3I70S & $2.80 \pm 0.28(7)$ & $\mathrm{T}$ & \\
\hline RyRI-C3402S & $3.36 \pm 0.38(7)$ & $A$ & \\
\hline RyRI-C3635 $A^{b}$ & $2.66 \pm 0.54(6)$ & & \\
\hline RyRI-5cys & $2.11 \pm 0.15(5)^{*}$ & & \\
\hline RyR I-7cys & $1.74 \pm 0.13(9)^{*}$ & & \\
\hline WT-RyR2 & $\mathrm{I} .07 \pm 0 . \mathrm{II}(6)^{*}$ & & \\
\hline
\end{tabular}

Notes: aCysteines mutated to serine in RyRI-5Cys; ' ${ }^{b}$ cysteines mutated to serine or alanine (C3635) in RyRI-7 Cys; ' $\mathrm{GSSG} / \mathrm{GSH}$ ratio corresponds to $\left[{ }^{3} \mathrm{H}\right]$ ryanodine binding ratio in presence of $5 \mathrm{mM} \mathrm{GSSG}$ and $5 \mathrm{mM} \mathrm{GSH}$ as described in the Methods section; ${ }^{d R y R 2}$ amino acid, present as cysteine in RyRI. Data are the mean \pm standard error of the mean of number of experiments in parentheses. $* P<0.05$ compared with WT-RyRI as determined by the paired Student's $t$-test.

Abbreviations: GSH, reduced glutathione; GSSG, oxidized glutathione; MS, mass spectrometry; RyRI, skeletal muscle type I; RyR2, cardiac muscle type 2.

reaching the minimal response determined for recombinant RyR2. The results suggest that the 18 cysteine mutations tested in the present study alone or in combination are not sufficient to eliminate the channel's response to a change in glutathione redox potential.

In conclusion, the results of the present study add to our understanding of the complex regulation of RyR1 by redox-active species. MS experiments identified a large fraction of free RyR1 thiols under the reducing conditions used in the present study. Replacement of reduced glutathione with oxidized glutathione suggested that cysteines that reacted with MBB may be present in a partially oxidized state, and that a change in glutathione redox potential shifts the redox state of cysteines to a more oxidized state, but without fully oxidizing the cysteines. Mutagenesis identified three redox-active cysteines but also indicated that additional cysteines participate in the redox regulation of RyR1. Further studies are required to understand the redox regulation of RyR1 more completely.
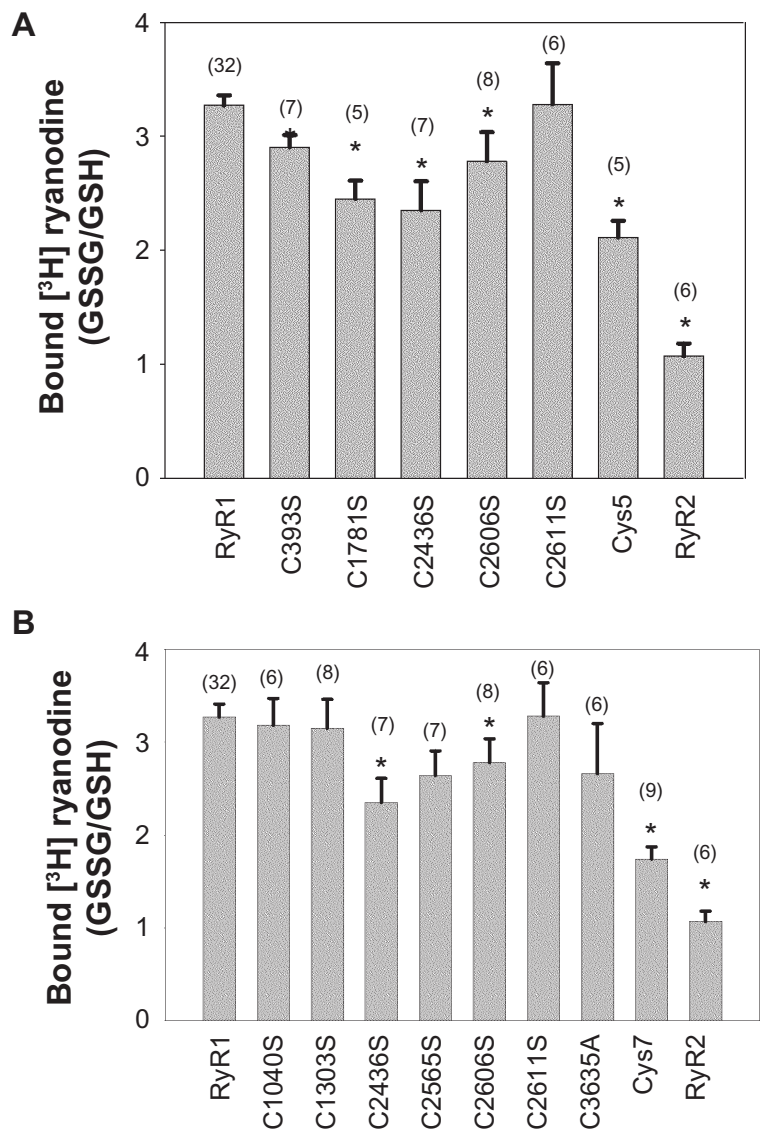

Figure $4\left[{ }^{3} \mathrm{H}\right]$ Ryanodine binding of wild-type RyRI, wild-type RyR2, and RyRI mutants in the presence of reduced and oxidized glutathione. The ratio of reduced to oxidized glutathione corresponds to the $\left[{ }^{3} \mathrm{H}\right]$ ryanodine binding ratio in the presence of $5 \mathrm{mM}$ oxidized glutathione and $5 \mathrm{mM}$ reduced glutathione, and was determined as described in the Methods section. Data are the mean \pm standard error of the mean of the number of experiments in parentheses of Table 2.

Note: $* P<0.05$ compared with wild-type RyRI as determined by the paired Student's $t$-test.

Abbreviations: GSH, reduced glutathione; GSSG, oxidized glutathione; RyRI, skeletal muscle type I; RyR2, cardiac muscle type 2.

\section{Acknowledgment}

This work was supported by a gift from an anonymous donor for research targeted at proteomics and cystic fibrosis and by a grant from the National Institutes of Health, AR018687.

\section{Disclosure}

The authors report no conflicts of interest in this work.

\section{References}

1. Reid MB. Reactive oxygen and nitric oxide in skeletal muscle. News Physiol Sci. 1996;11:114-119.

2. Ji LL. Exercise-induced oxidative stress in the heart. In: Sen CK, Packer L, Hanninen O, editors. Handbook of Exercise and Oxygen Toxicity. Amsterdam, The Netherlands: Elsevier Science; 2000.

3. Stamler JS, Meissner G. Physiology of nitric oxide in skeletal muscle. Physiol Rev. 2001;81:209-237.

4. Hidalgo C, Donoso P. Crosstalk between calcium and redox signaling: From molecular mechanisms to health implications. Antioxid Redox Signal. 2008;10:1275-1312. 
5. Meissner G. Regulation of mammalian ryanodine receptors. Front Biosci. 2002;7:d2072-d2080.

6. Treves S, Vukcevic M, Maj M, Thurnheer R, Mosca B, Zorzato F. Minor sarcoplasmic reticulum membrane components that modulate excitation-contraction coupling in striated muscles. J Physiol. 2009; 587:3071-3079

7. Eu JP, Sun J, Xu L, Stamler JS, Meissner G. The skeletal muscle calcium release channel: Coupled O2 sensor and NO signaling functions. Cell. 2000;102:499-509.

8. Feng W, Liu G, Allen PD, Pessah IN. Transmembrane redox sensor of ryanodine receptor complex. J Biol Chem. 2000;275:35902-35907.

9. Xia R, Stangler T, Abramson JJ. Skeletal muscle ryanodine receptor is a redox sensor with a well defined redox potential that is sensitive to channel modulators. J Biol Chem. 2000;275:36556-36561.

10. Durham WJ, Aracena-Parks P, Long C, et al. RyR1 S-nitrosylation underlies environmental heat stroke and sudden death in Y522S RyR1 knockin mice. Cell. 2008;133:53-65.

11. Bellinger AM, Reiken S, Carlson C, et al. Hypernitrosylated ryanodine receptor calcium release channels are leaky in dystrophic muscle. Nat Med. 2009;15:325-330.

12. Fauconnier J, Thireau J, Reiken S, et al. Leaky RyR2 trigger ventricular arrhythmias in Duchenne muscular dystrophy. Proc Natl Acad Sci USA 2010;107:1559-1564

13. Sun J, Xin C, Eu JP, Stamler JS, Meissner G. Cysteine-3635 is responsible for skeletal muscle ryanodine receptor modulation by NO. Proc Natl Acad Sci U S A. 2001;98:11158-11162.
14. Voss AA, Lango J, Ernst-Russell M, Morin D, Pessah IN. Identification of hyperreactive cysteines within ryanodine receptor type 1 by mass spectrometry. J Biol Chem. 2004;279:34514-34520.

15. Aracena-Parks P, Goonasekera SA, Gilman CP, Dirksen RT, Hidalgo C, Hamilton SL. Identification of cysteines involved in S-nitrosylation, S-glutathionylation, and oxidation to disulfides in ryanodine receptor type 1. J Biol Chem. 2006;281:40354-40368.

16. Petrotchenko EV, Pasek D, Elms P, Dokholyan NV, Meissner G, Borchers CH. Combining fluorescence detection and mass spectrometric analysis for comprehensive and quantitative analysis of redox-sensitive cysteines in native membrane proteins. Anal Chem. 2006;78: 7959-7966.

17. Meissner G. Adenine nucleotide stimulation of $\mathrm{Ca}^{2+}$-induced $\mathrm{Ca}^{2+}$ release in sarcoplasmic reticulum. J Biol Chem. 1984;259:2365-2374.

18. Gao L, Balshaw D, Xu L, Tripathy A, Xin C, Meissner G. Evidence for a role of the luminal M3-M4 loop in skeletal muscle $\mathrm{Ca}^{2+}$ release channel (ryanodine receptor) activity and conductance. Biophys J. 2000; 79:828-840

19. Takeshima H, Nishimura S, Matsumoto T, et al. Primary structure and expression from complementary DNA of skeletal muscle ryanodine receptor. Nature. 1989;339:439-445.

20. Nakai J, Imagawa T, Hakamata Y, Shigekawa M, Takeshima H, Numa S. Primary structure and functional expression from cDNA of the cardiac ryanodine receptor/calcium release channel. FEBS Lett. 1990; 271:169-177.

21. Sutko JL, Airey JA, Welch W, Ruest L. The pharmacology of ryanodine and related compounds. Pharmacol Rev. 1997;49:53-98.
Research and Reports in Biology

\section{Publish your work in this journal}

Research and Reports in Biology is an international, peer-reviewed, open access journal publishing original research, reports, editorials, reviews and commentaries on all areas of biology including animal biology, biochemical biology, cell biology, ecological studies, evolutionary biology, molecular biology, plant science and botany. The

\section{Dovepress}

manuscript management system is completely online and includes a very quick and fair peer-review system. Visit http://www.dovepress. com/testimonials.php to read real quotes from published authors. 